\title{
Ontogeny of Vestibular Compound Action Potentials in the Domestic Chicken
}

\author{
Sherri M. Jones and Timothy A. Jones \\ Department Surgery, Division of Otolaryngology, University of M issouri School of M edicine, Columbia, M 0 65212, USA
}

Received: 11 February 2000; Accepted: 14 August 2000; Online publication: 17 October 2000

\begin{abstract}
Compound action potentials of the vestibular nerve were measured from the surface of the scalp in 148 chickens ( $G$ allus domesticus). Ages ranged from incubation day 18 (E18) to 22 days posthatch (P22). Responses were elicited using linear acceleration cranial pulses. Response thresholds decreased at an average rate of $-0.45 \mathrm{~dB} /$ day. The decrease was best fit by an exponential model with half-maturity time constant of 5.1 days and asymptote of approximately -25.9 $\mathrm{dB}$ re: $1.0 \mathrm{~g} / \mathrm{ms}$. Mean threshold approached within 3 $\mathrm{dB}$ of the asymptote by ages P6-P9. Similarly, response latencies decreased exponentially to within $3 \%$ of mature values at ages beyond P9. The half-maturity time constant for peripheral response peak latencies P1, N1, and P2 was comparable to thresholds and ranged from approximately 4.6 to 6.2 days, whereas central peaks ( N2, P3, and N3) ranged from 2.9 to 3.4 days. Latency-intensity slopes for P1, N1, and P2 tended to decrease with age, reaching mature values within approximately 100 hours of hatching. Amplitudes increased as a function of age with average growth rates for response peaks ranging from 0.04 to $0.09 \mu \mathrm{V} /$ day. There was no obvious asymptote to the growth of amplitudes over the ages studied. Amplitude-intensity slopes also increased modestly with age. The results show that gravity receptors are responsive to transient cranial stimuli as early as E19 in the chicken embryo. The functional response of gravity receptors continues to develop for many days after all major morphological structures are in place. Distinct
\end{abstract}

Correspondence to: Dr. Sherri M. Jones - Department of Surgeryl ENT • University of Missouri School of Medicine - Rm 205 Allton Building, DC375.00 • 301 Business L oop 70W • Columbia, MO 65212. Telephone: (573) 884-6278; fax: (573) 884-4278; email: jonessh@health.missouri.edu maturational processes can be identified in central and peripheral neural relays. Functional improvements during maturation may result from refinements in the receptor epithelia, improvements in central and peripheral synaptic transmission, increased neural myelination, as well as changes in the mechanical coupling between the cranium and receptor organ.

Keywords: linear acceleration, birds, vestibular evoked potentials, gravity receptors, embryos, development, vestibular ontogeny, otolith organs

\section{INTRODUCTION}

The ontogeny of the peripheral vestibular system has been studied in numerous species including the bird. Many morphological and biochemical details of vestibular development have been described (see reviews by Anniko 1983, 1990; Peusner 1992; Dechesne 1992; Desmadryl et al. 1992). A number of investigators have evaluated the functional attributes of the developing vestibular periphery in the mammal (Romand and Dauzat 1982; Curthoys 1983; Desmadryl et al. 1986; Meza et al. 1996). Recent physiological studies of statoacoustic ganglion cells and canal hair cells in the developing bird have been described (Jones and Jones 2000b; M asetto et al. 2000); however, no detailed evaluation of the ontogeny of utricular and saccular function has been offered.

M orphological studies in the chick have established that the basic structural elements of the vestibular end organs are in place by at least incubation day 16 (EI6) (Knowlton 1967; Fink and Morest 1977; Ard and Morest 1984; Fermin and Cohen 1984; M eza and H inojosa 1987; Endo et al. 1993). However, the temporal pattern of functional onset and maturation for these elements is not clear. The purpose of the present study 
was to survey the normal pattern of vestibular functional development in the chicken (Gallus domesticus). To do this we measured thresholds, latencies, and amplitudes of the vestibular compound action potential at ages between E18 and three weeks posthatch. Our aim was to investigate the functional characteristics of primary afferent and central relay neural responses from the time gravity receptors begin to respond to transient cranial translation to three weeks posthatch. These measurements provided a means of evaluating the general sensitivity and maturity of gravity receptors as a function of age.

\section{METHODS}

Vestibular response measurements were performed on 148 chickens (Gallus domesticus). Forty-two embryos were studied. Eggs were obtained from commercial sources and incubated at $37.5^{\circ} \mathrm{C}$ at approximately $70 \%$ humidity. Eggs were turned automatically at 2-hour intervals during incubation. Hatchlings were housed in a commercial brooder and were provided food and water ad libitum.

Age was measured as the number of days from the beginning of incubation (set time) to the time of vestibular testing. For quantitative analysis, this was expressed as days post set (dps) and was available in 134 animals. In 14 animals, only the hatch and testing dates were available. In these cases, the mean period of incubation to hatch ( $22.03 \pm 0.87$ days, $n=79$ ) was added to the posthatch age to produce an unbiased estimator of dps. Traditional expressions for the day of incubation (e.g., E0, E1, E2) and posthatch day (e.g., P0, P1, P2) were also used to distinguish embryos and hatchlings where appropriate. Ages were measured with a resolution greater than whole 24-hour periods and, thus, are expressed here in fractional quantities where appropriate (e.g., E19.6, 24.4 dps). The completion of hatching was defined as the moment when animals first placed at least one foot on the cage surface (time of hatch). For the purpose of display and discussion, age was also expressed in hours relative to the mean hatch time across animals.

Posthatch birds were anesthetized with EquiThesin $(0.003 \mathrm{ml} / \mathrm{g})$ (Burkard et al. 1994; Jones et al. 1997, 1998) and embryos were anesthetized with EquiThesin:Saline (ratio 1 part: 4 parts, $0.1 \mathrm{ml}$ ). Tracheotomies were completed on posthatch birds. Stimuluscoupling to the cranium was accomplished the same way in hatchlings and embryos ( Fig. 1). The head of each animal was submerged in plaster (in embryos over $50 \%$ of the head was encased). When cured, the plaster provided a molded encasement of the beak and head as well as a solid continuous coupling with the platform. Movement of the platform was transferred
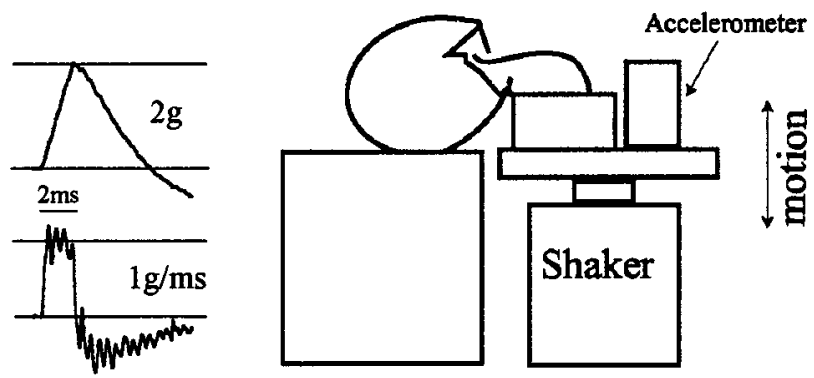

FIG. 1. Schematic illustration of the vestibular stimulus, stimulus shaker platform, and method of coupling stimuli to the cranium of animals. Left Stimulus: The accelerometer output during a stimulus pulse at $0 \mathrm{~dB}$ re: $1.0 \mathrm{~g} / \mathrm{ms}$ is represented in the top tracing. The accelerometer was mounted on the platform as shown on the right. With each stimulus, acceleration level increases linearly to reach a peak amplitude (here $2 \mathrm{~g}$ ) at $2 \mathrm{~ms}$. Lower curve is the first derivative of the acceleration trace (jerk in $\mathrm{g} / \mathrm{ms}$ ). Note the jerk pulse has a mean peak magnitude of $1.0 \mathrm{~g} / \mathrm{ms}$. Right Shaker and coupling: The anesthetized animal's head was submerged in plaster, which, upon curing, solidified to encase the beak and cranium. Although an embryo is illustrated here, the method was also used with posthatch birds. In the latter case, the animals were tracheotomized.

directly to the head in this manner. The head was embedded with the naso-occipital axis oriented vertically. In mostanimals, brain thermistorswere surgically implanted to monitor and maintain temperature at $39.0 \pm 0.1^{\circ} \mathrm{C}$. For those animals where brain temperature was not monitored, cloacal temperature was maintained within the same limits.

Vestibular compound action potentials recorded using the techniques described herein are also referred to as linear vestibular evoked potentials (linear VsEPs). Recording methods for the linear VsEP were described originally by Jones and Pedersen (1989) and Jones (1992) and have been modified as detailed elsewhere (Jones and Jones 1996; Jones et al. 1997, 1998; Nazareth and Jones 1998). We describe them here briefly. The adequate stimulusfor the linear VsEP is linear cranial jerk (the rate of change in acceleration per unit of time) in units of $\mathrm{g} / \mathrm{ms}[1.0 \mathrm{~g}=$ $9.81 \mathrm{~m} / \mathrm{s}^{2}=9.81 \mu \mathrm{m} / \mathrm{ms}^{2}$ (Jones et al 1998) ]. Linear jerk pulses ( 2 ms duration, Fig. 1) were presented to the bird's cranium via a mechanical shaker to which the bird's head was coupled as described above. Stimuli were presented in the naso-occipital axis ( $\pm G_{x}$ axis) at a rate of 2/ sor 9/s for embryos or posthatch birds, respectively. Normal and inverted stimulus polarities were used where normal polarity was defined as an initial upward movement of the platform and inverted as an initial downward movement. Maximum jerk amplitude was $1.0 \mathrm{~g} / \mathrm{ms}$ and levels were expressed in $\mathrm{dB}$ relative to $1.0 \mathrm{~g} / \mathrm{ms}(0 \mathrm{~dB}$ re: $1.0 \mathrm{~g} / \mathrm{ms}=1.0$ $\mathrm{g} / \mathrm{ms}$ ). The calculated magnitude of displacement that occurred during a rectangular 2-ms jerk at $0 \mathrm{~dB}$ was approximately $13 \mu \mathrm{m}$. Stimulus polarityand amplitude were monitored with a calibrated accelerometer 

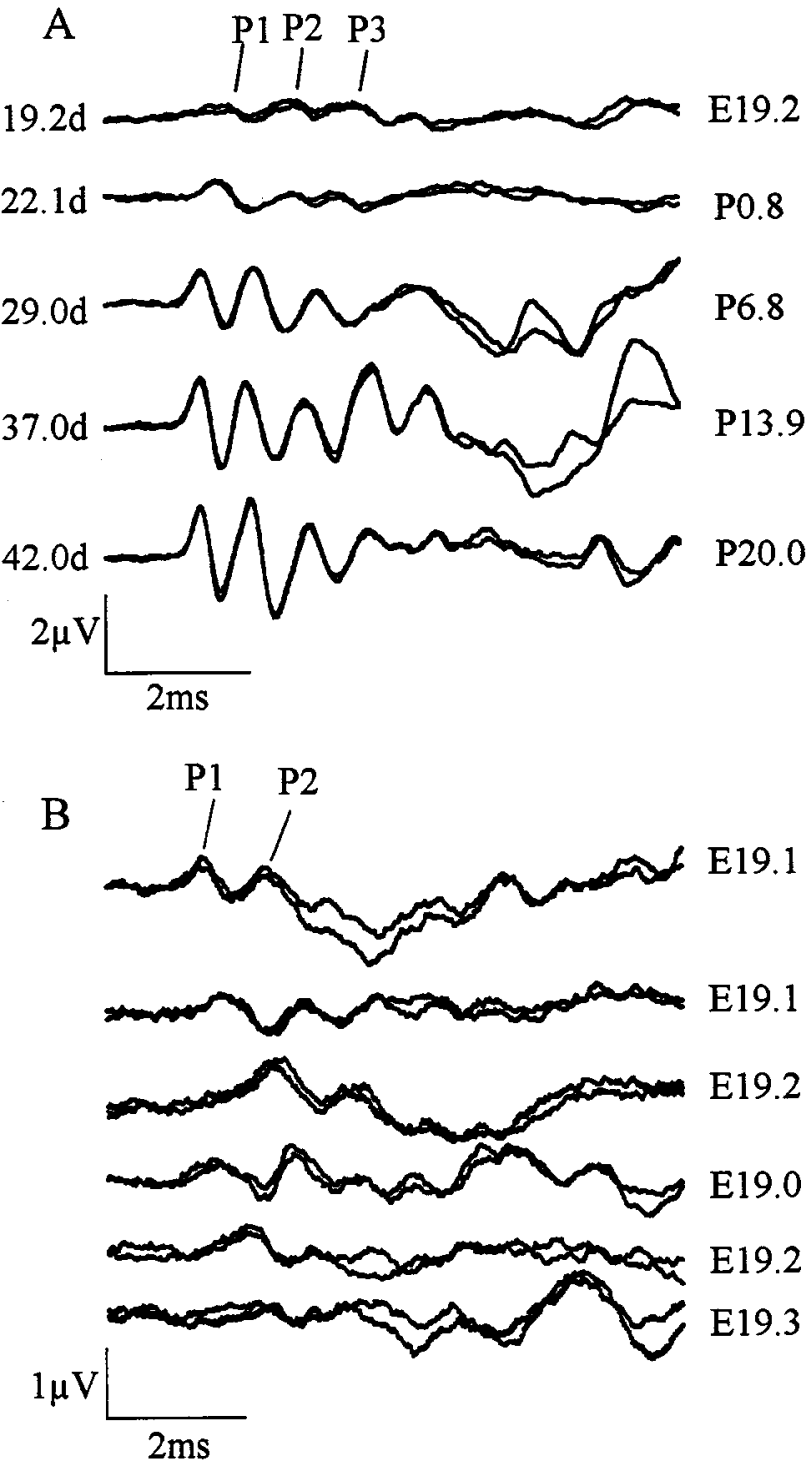

FIG. 2. A. Linear vestibular evoked potentials (VsEPs) were recorded at various ages in the chicken. Positive VsEP peaks are labeled (P1, P2, and P3). Age is represented in days postset (dps, left) and as incubation or posthatch day (right). Calibration bars reflect amplitude $(2 \mu \mathrm{V})$ and latency $(2 \mathrm{~ms})$ scales for response traces. Two response traces are superposed for each age to demonstrate reproducibility of waveforms. Collectively, these traces reflect the general qualitative changes throughout development in gravity receptor responses to transient linear acceleration stimuli. B. VsEPs from six embryos illustrate the high variability of responses at E19. Traces are plotted at a higher gain here as indicated by calibration bars ( $1 \mu \mathrm{V}, 2 \mathrm{~ms})$.

mounted on the platform. The output of the accelerometer was routed to an electronic differentiator to provide a direct online measure of jerk levels.

Subcutaneous electrodes were placed at the vertex (noninverting) and behind the left (inverting) and right (ground) external auditory meati. Electroencephalographic activity was amplified 200,000 times, filtered (bandpass $300-3000 \mathrm{~Hz},-6 \mathrm{~dB}$ points), and

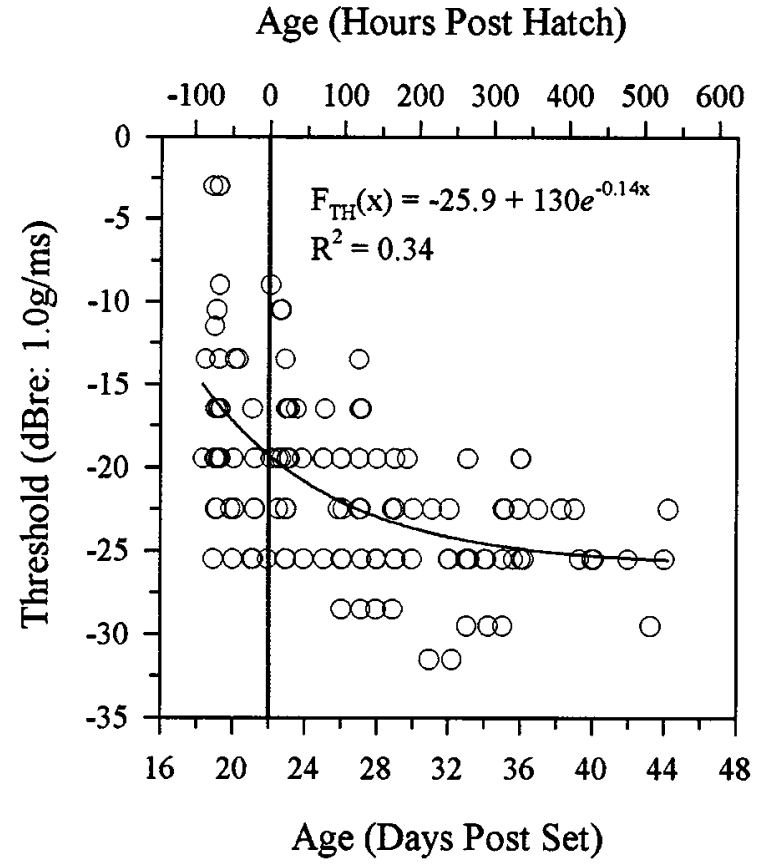

FIG. 3. Gravity receptor response threshold in $\mathrm{dB}$ re: $1.0 \mathrm{~g} / \mathrm{ms}$ is plotted as a function of age. The mean hatch date across all animals is shown as a vertical line at $22.03 \mathrm{dps}$ and 0 hours posthatch. The equation $F_{\mathrm{TH}}(x)$ is best fit to the decreasing threshold trend ( $p<$ 0.001 ). Thresholds approach within $3 \mathrm{~dB}$ of mature values at approximately 6-9 days posthatch.

digitized (1024 points at 8 or $16 \mu$ s per point). Averaged primary responses were obtained to 128 stimuli at a given intensity in the normal or inverted stimulus polarity. Responses were replicated such that at a given intensity four traces were collected. Two responses to normal stimuli and two responses to inverted stimuli were collected. Primary tracesfor normal and inverted stimuli were averaged offline to produce two final response traces at each stimulus intensity.

Vestibular compound action potentials, recorded as described here, have been shown to depend exclusively and critically on otoconial organs in the mammal (Jones et al. 1999). Moreover, it has been demonstrated in the bird (including the embryo) that responses are independent of both the cochlea and the lagena (Weisleder et al. 1990; Jones 1992; Jones and Jones 1996). For these reasons, and for reasons we have outlined elsewhere (Fermin et al. 1998), the linear VsEP is thought to be a measure of utricular and saccular function (i.e., a measure of gravity receptors excluding the avian lagena).

Quantitative measures of response peaks were analyzed statistically. Traditional linear regression, nonlinear regression, and curve-fitting algorithms ( $M$ arquardt-Levenberg, Sigma Plot 4.0) were used to evaluate and describe data. The first three positive and negative response peaks were scored to calculate response thresholds, peak latencies, and peak-to-peak 
amplitudes. Response thresholds provide a general measure of the sensitivity of gravity receptors; they were determined by systematically increasing stimulus intensity from approximately $0.021 \mathrm{~g} / \mathrm{ms}(-33 \mathrm{~dB}$ re: $1.0 \mathrm{~g} / \mathrm{ms}$ ) to $1.0 \mathrm{~g} / \mathrm{ms}(0 \mathrm{~dB}$ re: $1.0 \mathrm{~g} / \mathrm{ms})$ in $3-\mathrm{dB}$ steps. Threshold was defined as the stimulus intensity midway between the minimum intensity producing a response and the maximum intensity failing to produce a response. Peak latencies were defined as the time delay (in $\mu \mathrm{s}$ ) from stimulus onset to peak occurrence ( $P 1$ to $N 3$ ). L atency measures reflect the activation timing and conduction of neural impulses from the periphery through central relays ( $N$ azareth and Jones 1998). Peak-to-peak amplitudes (in $\mu \mathrm{V}$ ) were calculated by subtracting the amplitudes of negative peaks (N1 to N3) from the respective positive peaks (P1 to P3), thus providing a measure of the number and degree of synchronization of neurons activated. For each animal, amplitudes and latencies were expressed as a function of stimulus intensity and analyzed using linear regression. These measures characterized the relationship between the magnitude of stimulus input and response output. The results were expressed as amplitude-intensity (AI) and latencyintensity ( LI) slopesin $\mu \mathrm{V} / \mathrm{dB}$ and $\mu \mathrm{S} / \mathrm{dB}$, respectively. Response latencies, amplitudes, input-output slopes, and thresholds were also evaluated as a function of age. Nonlinear and linear regressions of response parameters on age were used to provide quantitative description of maturation rates.

\section{RESULTS}

Ages of animals studied ranged from approximately E18 to P22. Responses could not be resolved for ages younger than early E18. Indeed, four late E18-E19 embryosfailed to produce identifiable responses at the maximum stimulus intensity used ( $0 \mathrm{~dB}$ re: $1.0 \mathrm{~g} / \mathrm{ms}$ ).

Figure $2 a$ displays representative waveforms from age E19.2 to P20.0. Note the poorly resolved peaks, low amplitudes, and relatively late onset times for the youngest animals. Generally, response peaks had better resolution, larger amplitude, and earlier onset as the birds matured. Variation in embryonic response morphology was considerable, a fact which is better appreciated from Figure 2b.

Gravity receptor response thresholds decreased with increasing age, as illustrated in Figure 3. Based on a linear regression slope, threshold decreased at a rate of $-0.45 \mathrm{~dB} /$ day. Threshold data were best fit to an exponential function $\mathrm{F}_{\mathrm{TH}}(\mathrm{x})=\mathrm{y}_{0}+\mathrm{ae}^{-\mathrm{bx}}(\mathrm{p}<$ $\left.0.0001, R^{2}=0.34\right)$, where $x=$ age in dps, $y_{0}=-25.9$ $\mathrm{dB}$ re: $1.0 \mathrm{~g} / \mathrm{ms}$ as the asymptote, $b=0.136$ as the maturity rate coefficient, and $a=130$ as a scaling constant. The function is plotted in Figure 3. Using

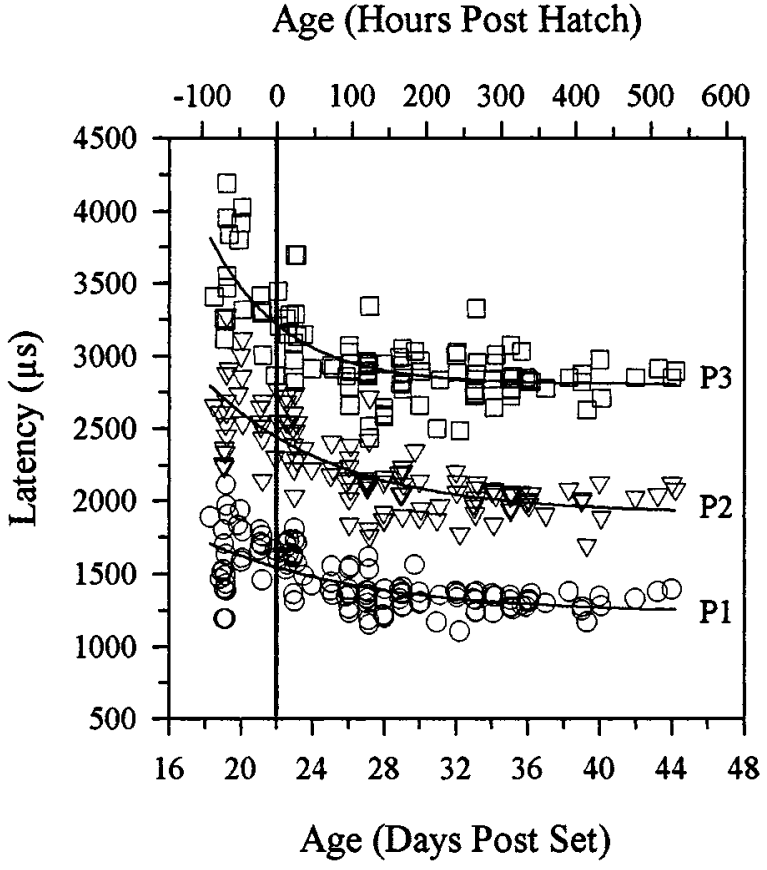

FIG. 4. Vestibular response latencies ( $\mu$ s) for positive peaks (P1, P2, and P3) are plotted as a function of age. The mean hatch date across all animals is shown as a vertical line at $22.03 \mathrm{dps}$ and 0 hours posthatch. Best-fit exponential regression functions are shown for each response peak $(p<0.001)$ and were of the form $F_{\mathrm{L}}(x)=y_{0}+$ $a e^{-b x}$ (where $x=$ time in dps). Similar results were obtained for N1, $\mathrm{N} 2$, and N3. Specific functions for each response peak are as follows: $\mathrm{P} 1=1226+3803 e^{-0.11 x}\left(R^{2}=0.45\right), \mathrm{N} 1=1549+11666 e^{-0.15 x}$ $\left(R^{2}=0.56\right), \mathrm{P} 2=1910+11040 e^{-0.14 x}\left(R^{2}=0.61\right), \mathrm{N} 2=2362+$ $48954 e^{-0.21 x}\left(R^{2}=0.65\right), \mathrm{P} 3=2800+80194 e^{-0.24 x}\left(R^{2}=0.57\right)$, $\mathrm{N} 3=3212+67028 e^{-0.23 x}\left(R^{2}=0.59\right)$. Stimulus was $0 \mathrm{~dB}$ re: 1.0 $\mathrm{g} / \mathrm{ms}$ in all cases.

$\mathrm{F}_{\mathrm{TH}}(\mathrm{x})$ and the mean hatch time of $22.03 \mathrm{dps}$, one can estimate the threshold at hatch to be $-19.3 \mathrm{~dB}$ re: 1.0 $\mathrm{g} / \mathrm{ms}$. The asymptote $y_{0}$ provides an estimate for linear VsEP mean threshold in mature animals. Together, these values describe a collective threshold that approaches one-half the distance toward maturity (i.e., the asymptote) every 5.1 days.

The relationship between latency and age is illustrated in Figure 4 where latency data for the first three positive peaks are displayed as a function of age. Latencies decreased with increasing age. Similar relationships held for negative peaks. Based on linear regression, the rate of decrease in P1 latency with age was approximately $-18.9 \mu \mathrm{s} /$ day. However, the decrease in latencies was best fit by the exponential function $\mathrm{F}_{\mathrm{L}}(\mathrm{x})=\mathrm{y}_{0}+\mathrm{a} \mathrm{e}^{-\mathrm{bx}}$. H alf-maturity time constants varied systematically such that early peaks $P 1$, $\mathrm{N} 1$, and P2 had substantially longer time constants $(6.16,4.58$, and 5.04 days, respectively) than later peaks ( $\mathrm{N} 2=3.38, \mathrm{P} 3=2.90, \mathrm{~N} 3=3.07$ days). The mean exponential maturity rate (b) for early peaks $(\mathrm{P} 1, \mathrm{~N} 1$, and $\mathrm{P} 2)$ was $0.13 \pm 0.02$ and was considerably 
less than the mean for later peaks N2, P3, and N3 $(0.22 \pm 0.02)$.

Gravity receptor response amplitudes increased steadily during maturation for all peaks. Figure 5 shows scatter plots of amplitudes for P1/ N1, P2/ N2, and P3/ $\mathrm{N} 3$ as a function of age. There was no clear evidence of an amplitude asymptote over the ages studied. Linear regression was used to describe the growth of response amplitudes. Mean amplitudes for P1/ N 1 increased at a rate of approximately $0.09 \mu \mathrm{V} /$ day. Estimates for the rate of growth in response amplitudes were similar for peaks $\mathrm{P} 1 / \mathrm{N} 1$ through N2/ P3, ranging from 0.08 to $0.09 \mu \mathrm{V} /$ day. P3/ N 3 had a growth rate approximately one-half of these values $(0.04 \mu \mathrm{V} /$ day).

The relationships between response measures and stimulus intensity, often referred to as input-output (I/ O) functions, were characterized for each animal. As reported elsewhere, vestibular response latencies decreased and amplitudes increased systematically as stimulus intensities were increased. To evaluate how these $1 / 0$ functions change with time, the linear regression slope of the I/ 0 function was plotted as a function of age for each respective peak. Figure 6 illustrates the results for $L I$ slopes. Figure 7 represents Al slope data.

With maturation, there was a general trend for mean LI slopes to become less steep (less negative) for the earliest peaks (Fig. 6). Changes in LI slope means, in large part, were due to the more negative slope values in embryos [mean $\pm \mathrm{SD}(\mathrm{n})$ in $\mu \mathrm{S} / \mathrm{dB}$ : embryos: $\mathrm{P} 1=-43 \pm 16$ (12); N $1=-44 \pm 17$ (13); $\mathrm{P} 2=-55 \pm 11$ (11) versus hatchlings: $\mathrm{P} 1=-30 \pm$ 6 (76); $\mathrm{N} 1=-41 \pm 8$ (78); $\mathrm{P} 2=-47 \pm 12$ (73) ]. Exponential functions provided the best fit to the maturational profile of $\mathrm{LI}$ slopes only for response peaks $\mathrm{P} 1, \mathrm{~N} 1$, and $\mathrm{P} 2$. There was no significant relationship between $\mathrm{LI}$ slope and age in later response peaks N2, $\mathrm{P3}$, and N3. In the latter cases, mean LI slopes had values between -45 and $-47 \mu \mathrm{s} / \mathrm{dB}$. Best-fit equations, asymptotes, and mean values are summarized in Figure 6 for all peaks. Generally, estimates of mature LI slopes were slightly steeper for peaks beyond $\mathrm{P} 1$ and $\mathrm{N} 1$.

Mean Al slopes increased with age for all peaks

FIG. 5. Vestibular response amplitudes $(\mu \mathrm{V})$ for three major peaks $(\mathrm{P} 1 / \mathrm{N} 1, \mathrm{P} 2 / \mathrm{N} 2$, and $\mathrm{P} 3 / \mathrm{N} 3)$ as a function of age. The mean hatch date across all animals is shown as a vertical line at $22.03 \mathrm{dps}$ and 0 hours posthatch. Linear regression functions were significant for all peaks $(p<0.001)$ and were of the form $F_{\mathrm{A}}(x)=m x+y_{0}$ (where $m=$ maturity rate in $\mu \mathrm{V} /$ day, $x=$ time in dps, and $y_{0}=$ intercept in $\mu \mathrm{V})$ are shown for each response peak. Similar results were obtained for N1/P2, N2/P3. Specific functions for the peaks not shown are $\mathrm{N} 1 / \mathrm{P} 2=0.08 x-1.03\left(R^{2}=0.43\right)$ and $\mathrm{N} 2 / \mathrm{P} 3=0.09 x-1.47$ $\left(R^{2}=0.54\right)$. Predicted amplitudes at $43 \mathrm{dps}(\mathrm{P} 21)$ were approximately $2.0 \mu \mathrm{V}$ for all peaks. Stimulus intensity was $0 \mathrm{~dB}$ re: $1.0 \mathrm{~g} / \mathrm{ms}$ in all cases.
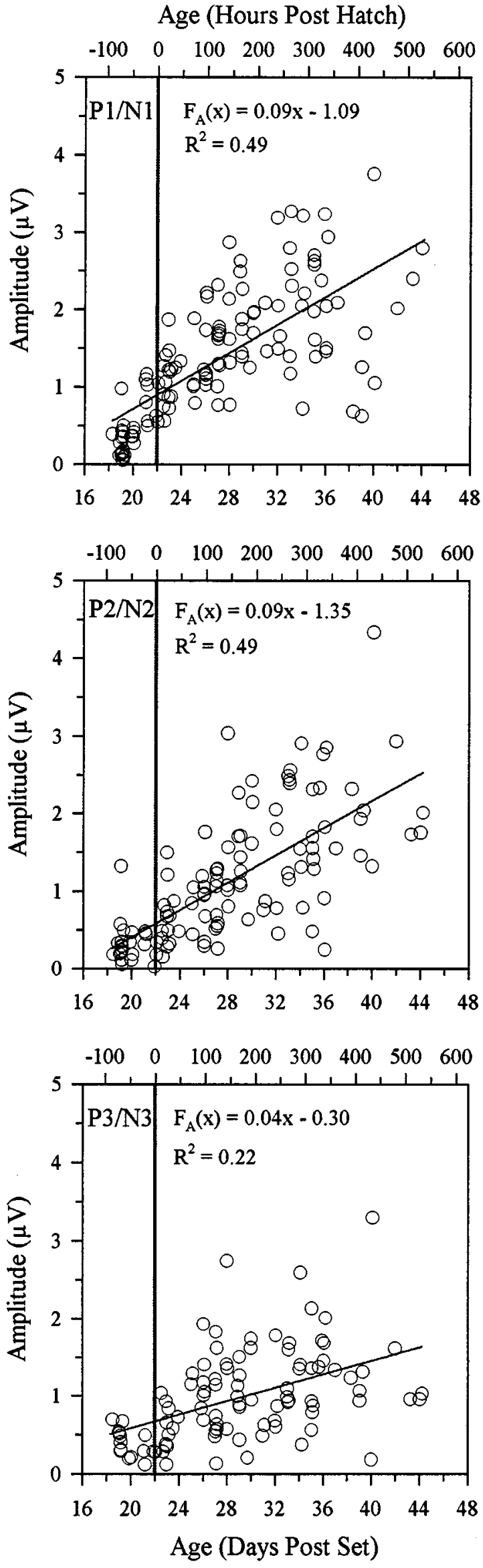
except P3/ N3 (Fig. 7). The rate of increase was comparable for most peaks ranging from 0.0025 to 0.0038 $\mu \mathrm{V} / \mathrm{dB} / \mathrm{dps}$. In the case of P3/ N 3, there was no significant change in slope with age and the mean value was approximately half those of the other peaks.

\section{DISCUSSION}

Considerable evidence suggests that all essential structural elements of the vestibular end organ, including differentiated hair cell types (I and II) and corresponding synaptic junctions, are in place by incubation day 16 in the chicken (Knowlton 1967; Fink and Morest 1977; Ginzberg and Gilula 1980; Ard and Morest 1984; Fermin and Cohen 1984; Meza and Hinojosa 1987). In all but one report (Endo et al. 1993), the appearance of type I hair cells and chalices were identified before El6. Virtually all investigators describe refinements in vestibular structural elements during periods beyond EI6 at least up to stage 46 (E21). Despite a consensus supporting the early formation of synaptic contacts in sensory epithelia, vestibular compound action potentials could be obtained consistently only in animals approaching EI9 and older. Response thresholds were above $1.0 \mathrm{~g} / \mathrm{ms}$ (our most intense stimulus level) in approximately $10 \%$ of the animals, even at late E18. Moreover, a progressive maturation of some response measures continued into and beyond the second posthatch week. These findings suggest that gravity receptors are responsive to stimuli as early as E19, but they remain, to some extent, functionally immature for a substantial period after the principle structural elements have been established. These observations confirm and significantly extend earlier reports (Jones and Jones 1996).

The current results also provide evidence that central and peripheral vestibular relays have some distinct maturational profiles. Vestibular response peaks

FIG. 6. Latency-intensity (LI) slopes ( $\mu \mathrm{s} / \mathrm{dB}$ ) for three positive peaks (P1, P2, and P3) are plotted as a function of age. The mean hatch date across all animals is shown as a vertical line at $22.03 \mathrm{dps}$ and 0 hours posthatch. Best-fit exponential regression functions $(p<$ $0.001)$ are shown for $\mathrm{P} 1$ and $\mathrm{P} 2$. These are of the general form $F_{\mathrm{LI}}(x)=y_{0}+a\left(1-e^{-b x}\right)$, where $x=$ age in days postset (dps). Asymptotes for $\mathrm{P} 1$ and $\mathrm{P} 2$ are equal to $y_{0}+a$ or -27 and $-40 \mu \mathrm{s} /$ $\mathrm{dB}$, respectively. Half-maturity time constants for P1 and P2 were 2.6 and 4.2 days, respectively. The regression equation for $\mathrm{N} 1 \quad(p<$ 0.001 , not shown) was $F_{\mathrm{LI}}(x)=-92+60\left(1-e^{-0.071 x}\right)$, where the asymptote $=32 \mu \mathrm{s} / \mathrm{dB}$ and half-maturity time constant $=9.8$ days . For response peaks P3 (bottom graph) and N2 and N3 (not shown), the relationship between $\mathrm{LI}$ slope and age was not significant. In these cases the mean values \pm SD were calculated as follows: $\mathrm{N} 2=-46 \pm 8.8 \mu \mathrm{s} / \mathrm{dB} ; \mathrm{P} 3$ (shown); N3 $=-46 \pm 11.2 \mu \mathrm{s} / \mathrm{dB}$.
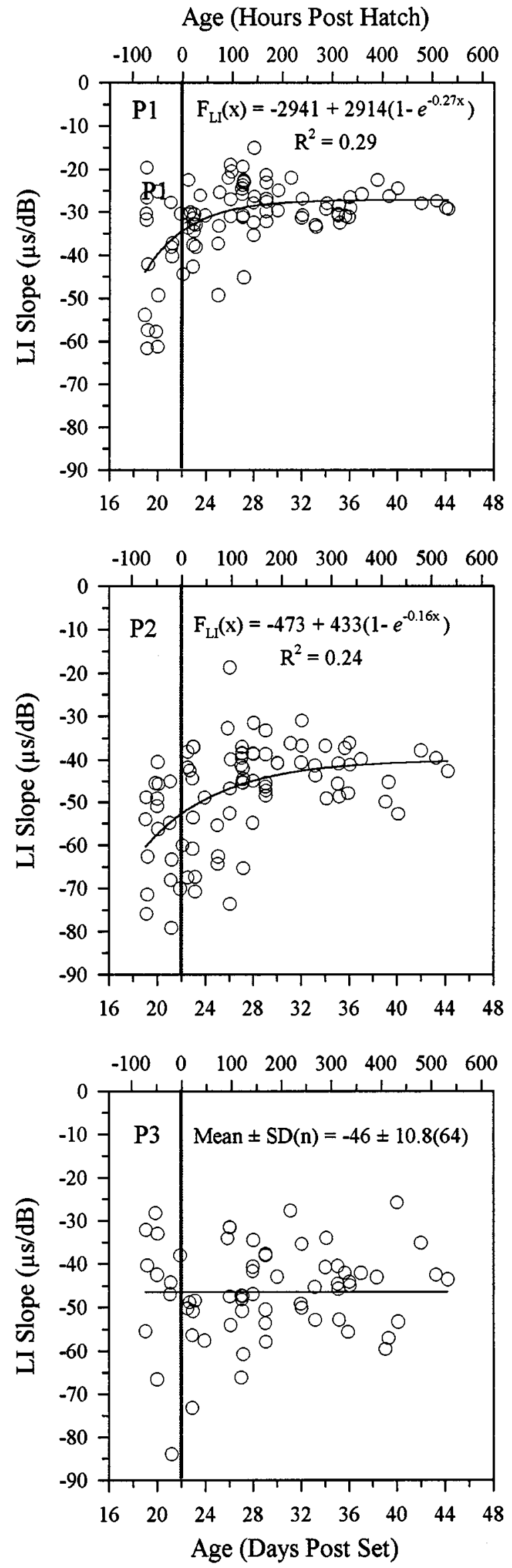
beyond $\mathrm{P} 2$ have been shown to depend critically on central brainstem structures (Nazareth and Jones 1998). In contrast, P1 and N 1 remained after destruction of central vestibular nuclei or isolation of central relays from the eighth nerve, demonstrating that these early peaks reflect functional activity exclusively in the peripheral nerve. In the same studies, P2 had properties suggesting mixed peripheral and central origins. Here we report that maturational rate constants for peripheral early peaks are different from those of later peaks associated with activity of central relay neurons. This is illustrated in the exponential curves of Figure 4. The amount of latency decrease per unit time for ages up to approximately 100 hours posthatch is much greater for peaks having exclusively central origins (i.e., those later than P2) compared with peripheral response components $P 1$ and $N 1$. Latencies of $P 2$ exhibit a maturation rate closest to those of peripheral response elements.

Maturation rates for $\mathrm{P} 1, \mathrm{~N} 1$, and $\mathrm{P} 2$ latencies are quite similar to the rate of maturation for thresholds, suggesting the possibility that latency decreases for these response peaks may in part depend on threshold decreases. In contrast, maturation rates for central peaks later than P2 suggest that some additional central process (i.e., beyond peripheral threshold decreases) is likely operating to change latencies in central vestibular relays.

In an attempt to better isolate the quantitative contributions from central brainstem maturational processes, we subtracted latencies of a peripheral peak (N1) from central peaks (N2, P3, and N3) for all animals. By removing (i.e., subtracting) the influence of the latest peripheral component (i.e., N1), changes in central systems may be viewed in isolation. In addition, we subtracted $\mathrm{P} 1$ from $\mathrm{N} 1$ and $\mathrm{N} 1$ from $\mathrm{P} 2$ to isolate processes within the eighth nerve (Fig. 8). The P2-N 1 latency difference likely represents the initial process of central activation and/ or the termination of peripheral events.

FIG. 7. Amplitude-intensity (AI) slopes $(\mu \mathrm{V} / \mathrm{dB})$ for three response peaks (P1/N1, P2/N2 and P3/N3) as a function of age are represented. The mean hatch date across all animals is shown as a vertical line at $22.03 \mathrm{dps}$ and 0 hours posthatch. The linear regression of Al slope on age was significant $(p<0.001)$ for all peaks except P3/N3 (bottom graph). In the latter case, the graph represents the mean across all animals, and the mean $\pm \mathrm{SD}(n)$ is shown. Linear regression functions of the form $F_{\mathrm{Al}}(x)=m x+y_{0}$ for Al slope versus age are shown for $\mathrm{P} 1 / \mathrm{N} 1$ (top) and P2/N2 (middle). Linear functions for peaks not shown are as follows: $\mathrm{N} 1 / \mathrm{P} 2=0.0027 x+0.000\left(R^{2}=0.21\right)$ and $\mathrm{N} 2 /$ $\mathrm{P} 3=0.0025 x-0.020\left(R^{2}=0.24\right)$, where $x=\mathrm{dps}, m=$ slope in $\mu \mathrm{V} / \mathrm{dB} / \mathrm{dps}$ and $y_{0}=$ intercept in $\mu \mathrm{V} / \mathrm{dB}$. At $43 \mathrm{dps}$ (P21), the estimates for mature values in $\mu \mathrm{V} / \mathrm{dB}$ are $\mathrm{P} 1 / \mathrm{N} 1=0.13, \mathrm{~N} 1 / \mathrm{P} 2=0.12, \mathrm{P} 2 /$ $\mathrm{N} 2=0.11$, and $\mathrm{N} 2 / \mathrm{P} 3=0.09$.
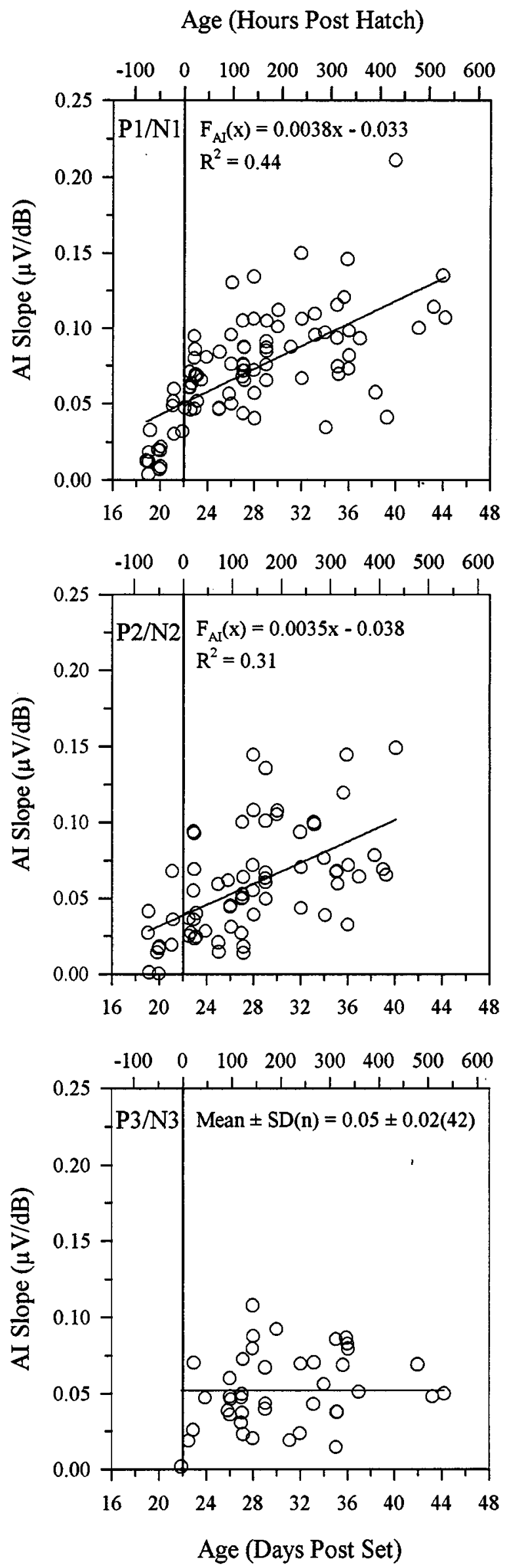

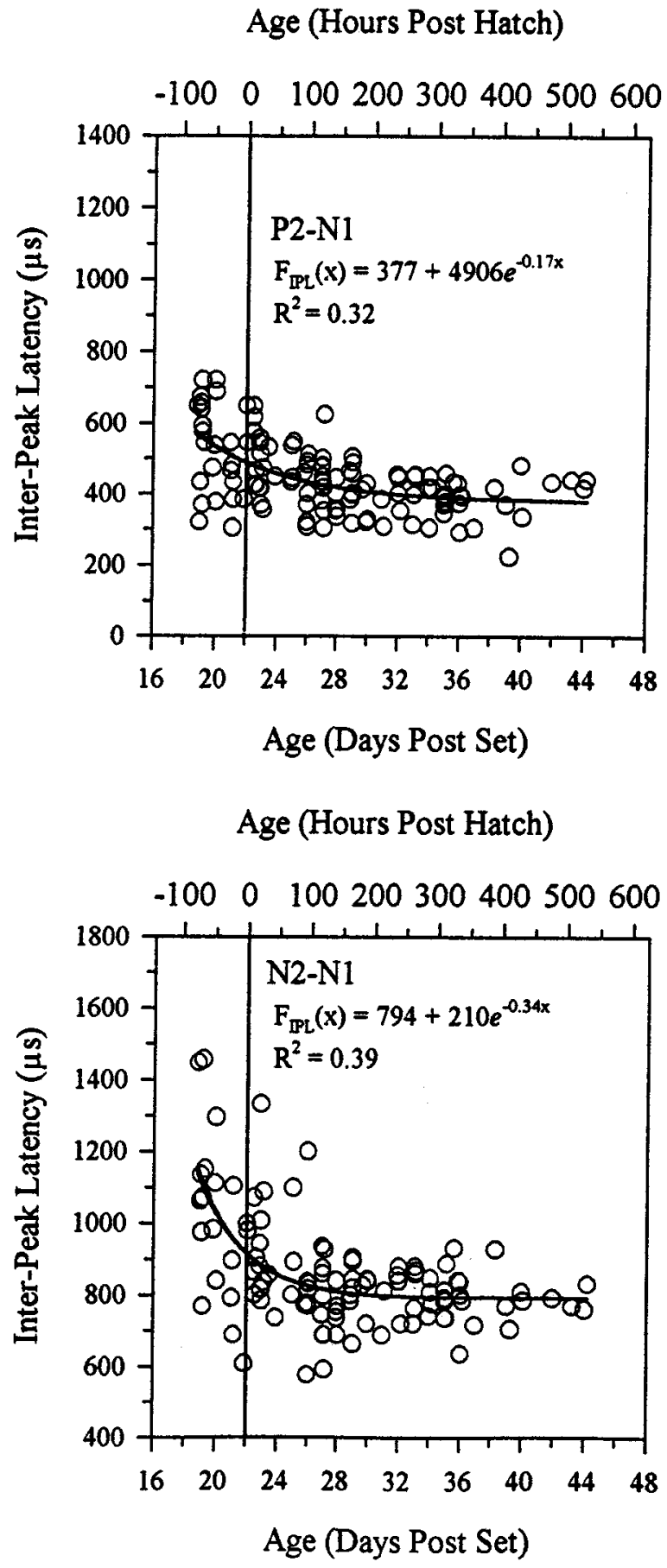

FIG. 8. Vestibular response interpeak latencies (IPLs, $\mu \mathrm{s})$ for P2-N1 and $\mathrm{N} 2-\mathrm{N} 1$ as a function of age. The mean hatch date across all animals is shown as a vertical line at $22.03 \mathrm{dps}$ and 0 hours posthatch. Best-fit exponential regression lines of the form $F_{\mathrm{IPL}}(x)=y_{0}+a e^{-b x}$ (where $x=$ time in dps) are shown $(p<0.001)$. Specific functions for peaks not shown are as follows: N1-P1 $=298+4830 e^{-0.18 x}$ $\left(R^{2}=0.36\right), \mathrm{P} 3-\mathrm{N} 1=1202+7,352,161 e^{-0.52 x}\left(R^{2}=0.27\right), \mathrm{N} 3-$ $\mathrm{N} 1=1622+1,107,073 e^{-0.41 x}\left(R^{2}=0.29\right)$.

The distributions of N1-P1 and P2-N1 interpeak latencies (IPLs) were very similar, indicating a slight decrease in latencies resulting from the processes within the nerve itself. They also indicate that $\mathrm{P} 2$ latenciesare very closely tied to changes in the eighth nerve. The small steady shiftsin latency for these early components may correspond to maturational refinements in myelin or other processes affecting eighth nerve conduction velocities. These changes are independent of threshold shifts and processes associated with mechanical coupling, transduction, and transmission across the hair cell-primary afferent synapse.

Latency changes in central relays were more dramatic than those of the periphery. Exponential curves fit to the central IPL data (N2-N1, P3-N1, N3-N1) reveal maturational rate constants $(0.336,0.524$, and 0.415 respectively) two to three times larger than those indicated for eighth nerve refinements $(0.175$ and 0.172 for $\mathrm{N} 1-\mathrm{P} 1$ and $\mathrm{P} 2-\mathrm{N} 1$, respectively) during this period. Moreover, the data suggest that central changesare maximal at embryonic and early posthatch ages. All changes in central brainstem latencies ap pear to be minimal beyond the age of 100 hours posthatch (Fig. 8). IPLs for N3-N 1 and P3-N1, although not shown in Figure 8, demonstrated a similar time course to that of N2-N1. These analyses suggest that shifts in latency occurring after 100 hours posthatch are likely associated with peripheral threshold decreasesand not continuing central refinement. The original data shown in Figure 4 show gradual decreases in latencies well beyond 100 hours posthatch. These latency shifts cannot be due to continued central maturation since that processisminimal during these ages. On the other hand, response thresholds continue to decrease well beyond 100 hours posthatch and, therefore, provide a reasonable explanation for latency improvements during this time.

Response amplitudes increased generally as a function of age for all peaks. The range of amplitudes increased during maturation and there was considerable variation in older animals, a feature commonly noted for measurements of compound action potentials in general (Fig. 5). Despite this variation, the rate of growth for response amplitudes for most peaks was very similar. Notably absent in the present data are clear mature asymptotes. This suggests the possibility that amplitudes continue to increase at ages beyond those studied here.

The basis for long and continued average increases in response amplitudes is not clear. Threshold shifts are not likely to explain increased amplitudes completely since threshold changes little after 10 days posthatch yet amplitudes appear to continue to increase thereafter. The increase in amplitudes may be explained by an increase in the number of cells contributing to responsesand/ or by improvements in neural discharge synchronization. It is important to note that the number of hair cells in the epithelium of the utricle continues to increase posthatch in chickens 
(Goodyear et al. 2000). Whether this is the basis for the growing neural response amplitudes posthatch remains an open question.

Maturational changes in $\mathrm{LI}$ functions beyond the first 100 hours posthatch are quite modest if present at all (Fig. 6). Indeed, if embryos are excluded, LI slopes appear to be essentially independent of age. In contrast, Al slopes increased slightly for most peaks through post hatch periods (Fig. 7).

The changes in vestibular responses after E 19 may partly reflect the final refinements of peripheral sensory elements. These may include changes in the epithelium, including ion channel kinetics and distributions in hair cells (Masetto et al. 2000; Griguer and Fuchs 1996), late maturation of synaptic contacts, and increased myelination of afferent neurons (Knowlton 1967; Fermin and Cohen 1984; Peusner et al. 1988; Endo et al. 1993; Peusner and Giaume 1996).

Other maturational processes affecting response thresholds during this period may include dimensional changes in the labyrinth during growth as well as changes in otoconial membranes and mechanical coupling between hair cell stereocilia, overlying structure, and cranium (Fermin et al. 1990; Cohen 1993). Some of these factors may be related to development and ossification of the skull. Jollie (1957) and Hogg $(1978,1990)$ have described ossification, pneumatization, and articulation of the chicken skull in great detail. In general, the onset of ossification begins as early as E9/E10 for the squamous bone up to E16 for the opisthotic and epiotic bones. These latter two bones, along with the prootic bone, encase the inner ear. The prootic bone and the remaining skull areas (e.g., frontal, parietal, supraoccipital, exoccipital, and basioccipital) begin ossifying at various times between E11 and EI5. Jollie ( 1957) reported that the most rapid changes in skull development occur between E12 and E17. Following the onset of ossification, pneumatization begins two to three days later. ByE 19/ E20, ossification is seen throughout the skull and pneumatization is extensive in all areas except the frontal, basioccipital, pleurosphenoid, orbitosphenoid, mesethmoid, and mandible. These regions begin pneumatizing 35-120 days posthatch. O ssification of the skull continues until chickens are fully grown since fusion of the skull bones does not occur until 80 or more days posthatch, except for the basiocciptial/ exoccipital juncture which fuses 39 days posthatch (Hogg 1978).

It is not clear from the foregoing paragraph precisely how or whether skull ossification and pneumatization actually affect response maturation. In the embryo, there is no a priori requirement for an ossified skull given the means of stimulus coupling in the present study (head encased in plaster). Even if the head had a consistency comparable to that of body fluids, a plaster enclosure of the fluid would accelerate the entire mass during stimulation. During such stimulation, the density difference between otoconial matrix and surrounding tissue would certainly cause shearing action at the boundary between the two compartments. The critical requirement is that otoconia be present. That condition is satisfied well before responses begin, since otoconia appear at stage 28 , very early in development (E5) (De Vincentiis and Marmo 1968; Fermin et al. 1987). The question then becomes one of mechanical compliance of the tissue. All embryos in the present work were studied prior to the onset of pulmonary ventilation and prior to clearing of fluid from the middle ears. Therefore, in these and all younger embryos, all potential pneumatic space is fluid-filled. As a result, the presence of "compressible" space is likely minimal in embryos and stimuli would be readily transmitted to the inner ear. Presumably, by the time a significant amount of fluid is actually removed from pneumatic spaces and thus are potentially compressible (i.e., after E20 at about the time of hatch), ossification of cranial bones is sufficient to transmit forces to inner ear compartments since responses were present at this age.

Based on the present results, most developmental changes in the VSEP- particularly those for latencies at $0 \mathrm{~dB}$ re: $1.0 \mathrm{~g} / \mathrm{ms}$, LI slopes, and thresholds-are completed or approach mature values well within 10 days posthatch (P10), whereas ossification and pneumatization continue for much longer periods. O ssification beyond P10, therefore, would seem to play little role in maturational changes in the VsEP. However, between E19 and P10, ossification may contribute to improvementsin peripheral sensitivity to cranial stimulation, consequently affecting response parameters influenced by thresholds. The appearance of significant ossification by E19/ E20 does correspond to the onset of the VSEP in the present study and it may be an important event. However, as argued above, this would not seem to be an a priori requirement for the VsEP in the embryo.

Threshold changes alone cannot explain many obser vations of the present study. For example, amplitudes and Al functions continue to grow during periods where changes in thresholds, latencies, and LI functions are minimal and approximate mature values. Moreover, there are independent central changes which likely depend on central refinements that lead to improved synaptic transmission, neural activation, and conduction.

Studies of nonauditory and auditory primary afferents of the statoacoustic ganglion in the chicken embryo have underscored the remarkable maturity of activity patterns in late embryos E19 and older (Jones and Jones 2000b). These studies also revealed many immaturities in activity patterns including irregular 
neural bursting, low spontaneous discharge rates, prolonged spike dead times, and modal interspike intervalsin late embryos. M echanismsoperating to produce such immature discharge patterns in single neurons may also be the basis for slower conduction velocities and reduced capacitiesfor neural synchronization suggested by results of the present study.

There have been similar observations in mammals. Studies of single vestibular primary afferents in newborn rats have revealed a number of immature features in neural firing patterns (Curthoys 1983). These studies reported highly variable single unit responses, decreased sensitivities and gain, and delayed timing and phase lags for neural activation. The reduced amplitudes, elevated thresholds, and delayed latencies of vestibular compound action potentials reported here might be indicative of similar immaturity in avian embryonic neurons.

Less easily explained is the difficulty of recording responses at ages earlier than E19. This observation is in striking contrast to embryonic auditory compound action potentials which reportedly were measured in avian embryos as young as E12 (Saunders et al. 1973). Although a number of hypotheses may be entertained to explain this, including stimulus coupling between cranium and receptor epithelium, one of the most intriguing possibilities is that some unknown critical sensory element is finally engaged in the vestibular neuroepithelium at approximately E19. It is clear from studies of individual primary afferents of the statoacoustic ganglion that a major transformation takes place in the embryo at about E18. The transformation in auditory ganglion cells is unrelated to stimulus coupling (i.e., middle ear function). New evidence suggests that in animals younger than E18, rhythmic slow bursting patterns of spontaneous neural discharge change to irregular bursting patterns as animals approach the age of E19 (Jones and Jones 2000a). Furthermore, relatively mature regular discharge activity can be seen in nonauditory (presumably vestibular) neurons at E19 (Jones and Jones 2000b). Understanding this period of vestibulocochlear development is of great interest and remains a target for future research.

\section{ACKNOWLEDGMENTS}

This work was supported by NASA Life Sciences Division Grants NAG2-1032, NAGW 1275, NASA NAGW 3910, NASA NAG5 4607.

\section{REFERENCES}

ANNIKO M. Embryonic development of vestibular sense organs and their innervation. In: R Romand (ed) Development of Auditory and Vestibular Systems. Academic Press, New York, 375-423, 1983.
ANNiko M. Development of the vestibular system. In: JR Coleman (ed) Development of Sensory Systems in Mammals. John Wiley \& Sons, New York, 341-400, 1990.

ARD MD, MoREST DK. Cell death during development of the cochlear and vestibular ganglia of the chick. Int. J. Dev. N eurosci. 2:535-547, 1984.

BURKARD R, JONES SM, JONESTA. Conventional and cross-correlation brain-stem auditory evoked responses in the white leghorn chick: Rate manipulations. J. Acoust. Soc. Am. 95(4):2136-2144, 1994.

COHEN GM. Structure of avian tectorial, otolithic, and cupular membranes. Physiologist. 36:79-80, 1993.

CURTHOYS IS. The development of function of primary vestibular neurons. In: R Romand Development of Auditory and Vestibular Systems. Academic Press, New York, 425-461, 1983.

DECHESNE CJ. The development of vestibular sensory organs in human. In: R Romand (ed) Development of Auditoryand Vestibular Systems 2. Elsevier Amsterdam 419-446, 1992.

DeSmadRYL G, DeCheSNe CJ, RAYMond J. Recent aspects of development of the vestibular sense organs and their innervation. In: Romand R (ed) Development of Auditory and Vestibular Systems 2. Elsevier, Amsterdam 461-482, 1992.

DESMADRYL G, RAYMOND J, SANS A. In vitro electrophysiological study of spontaneous activity in neonatal mouse vestibular ganglion neurons during development. Dev. Brain Res. 25:133-136, 1986.

DE VINCENTIIS M, MARMO R. Inhibition of the morphogenesis of the otoliths in the chick embryo in the presence of carbonic anhydrase inhibitors. Experientia 24:818-820, 1968.

Endo S, Sekitani T, Kido T, Ogata Y. Development of the chick vestibular ganglion and its nerve terminating in the endorgan. Acta Otolaryngol. (Stockh.) 503:170-173, 1993.

Fermin CD, Cohen GM. Development of the embryonic chick's statoacoustic ganglion. Acta Otolaryngol. 98:42-52, 1984.

Fermin CD, IgARASH I M, Yoshihara T. Ultrastructural changes of statoconia after segmentation of the otolithic membrane. Hear. Res. 28:23-34, 1987.

Fermin CD, LOVETT AE, I garashi M, DUNneR K. Immunohistochemistry and histochemistry of the inner ear gelatinous membranes and statoconia of the chick [ Gallus domesticus] . Acta Anat. 138:7583, 1990.

Fermin CD, Lychakov D, Campos A, Hara H, Sondag E, Jones T, Jones S, TAYLor M, MEZA-RUIZ G, MaRTIN DS. Otoconia biogenesis, phylogeny, composition and functional attributes. $\mathrm{H}$ istol. $\mathrm{H}$ istopathol. 13:1103-1154, 1998.

FINK DJ, MOREST DK. Formation of synaptic endings by colossal fibers in the vestibular epithelium of the chick embryo. Neuroscience 2:229-252, 1977.

GINZBERG RD, GILULA NB. Synaptogenesis in the vestibular sensory epithelium of the chick embryo. J. Neurocytol. 9:405-424, 1980.

Goodyear R, Gates R, LUKASH KIN A, RICHARDSON G. Hair-cell numbers increase by $35 \%$ in the utricular macula of the domestic chicken during the first 16 weeks after hatching. Assoc. Res. O tolaryngol. Abstr. 23:247, 2000.

Griguer C, Fuchs PA. Voltage-dependent potassium currents in cochlear hair cells of the embryonic chick. J. Neurophysiol. 75:508-513, 1996.

HOGG DA. The articulations of the neurocranium in the postnatal skeleton of the domestic fowl (Gallus gallus domesticus). J. Anat. 127:53-63, 1978.

HoGG DA. The development of pneumatisation in the skull of the domestic fowl (Gallus gallus domesticus). J. Anat. 169:139-151, 1990.

JOLLIE MT. The head skeleton of the chicken and remarks on the anatomy of the region in other birds. J. Morphol. 100:389-436, 1957.

Jones SM, Erway LC, Bergstrom RA, Schimenti JC, Jones ta. Vestibular responses to linear acceleration are absent in otoconia- 
deficient C57BL/6JEi-het mice. Hear. Res. 135:56-60, 1999, DOI:10.1016/ S0378-5955, (99), 00090-8.

JONES SM, JONES TA. Short latency vestibular evoked potentials in the chicken embryo. J. Vestib. Res. 6:71-83, 1996, DOI:10.1016/ 0957-4271, (95), 02008-X.

JONES SM, JONES TA. Bursting discharge patterns of cochlear ganglion cells in the E15-E18 chicken embryo. Assoc. Res. O tolaryngol. Abstr. 23:248, 2000a.

JONES SM, JONES TA, SHUKLA R. Short latency vestibular evoked potentials in the Japanese quail (Coturnix coturnix japonica). J. Comp. Physiol. A. 180:631-638, 1997, DOI: 10.1007/ s003590050079.

JONESTA. Vestibular short latency responses to pulsed linear acceleration in unanesthetized animals. Electroenceph. Clin. Neurophysiol. 82:377-386, 1992.

JONES TA, JONES SM. Spontaneous activity in the statoacoustic ganglion of the chicken embryo. J. Neurophysiol. 83:1452-1468, 2000b.

Jones TA, JONEs SM, Colbert S. The adequate stimulus for avian short latency vestibular responses to linear translation. J. Vestib. Res. 8:253-272, 1998, DOI:10.1016/ S0957-4271, (97), 00072-4.

Jones TA, PEDERSEn TL. Short latency vestibular responses to pulsed linear acceleration. Am. J. Otolaryngol. 10:327-335, 1989.

KNOWLTON VY. Correlation of the development of membranous and bony labyrinths, acoustic ganglia, ner ves, and brain centers of the chick embryo. J. Morphol. 121:179-208, 1967.

Masetto S, Perin P, Malusa G, Zucca G, Valli P. Membrane properties of chick semicircular canal hair cells in situ during embryonic development. J. Neurophysiol. 83:2740-2756, 2000.
Meza G, Acuna D, Gutierrez A, Merchan JM, Rueda J. Development of vestibular function: biochemical, morphological and electronystagmographical assessment in the rat. Int. J. Dev. Neurosci. 14:507-513, 1996, DOI:10.1016/ 0736-5748, 95, 00099-2.

MEZA G, H INojOSA R. Ontogenetic approach to cellular localization of neurotransmitters in the chick vestibule. Hear. Res. 28:7385, 1987.

NazAReth AM, Jones TA. Central and peripheral components of short latency vestibular responses in the chicken. J. Vestib. Res. 8:233-252, 1998, DOI:10.1016/ S0957-4271, (97), 00076-1.

PEUSNER KD. Development of vestibular brainstem nuclei. In: ROMAND R ( ed) Development of Auditory and Vestibular Systems 2. Elsevier Amsterdam 489-518, 1992.

Peusner KD, Giaume C. Dendritic growth and changes in electrophysiological properties during development of chick vestibular neurons. Ann. NY Acad. Sci. 781:677-679, 1996.

Peusner KD, Lindberg NH, Mansfield PF. Ultrastructural study of calycine synaptic endings of colossal vestibular fibers in the cristae ampullares of the developing chick. Int. J. Dev. Neurosci. 6:267283, 1988.

ROMAND R, DAUZAT M. Modification of spontaneous activity in primary vestibular neurons during development in the cat. Exp. Brain Res. 45:265-268, 1982.

Saunders JC, Coles RB, Gates RG. The development of auditory evoked responses in the cochlea and cochlear nuclei of the chick. Brain Res. 63:59-74, 1973.

Weisleder P, Jones TA, Rubel EW. Peripheral generators of the vestibular evoked potentials [VSEP] in the chick. Electroenceph. Clin. Neurophysiol. 76:362-369, 1990. 